\title{
Increasing deaths from colorectal cancer in Poland - Insights for optimising colorectal cancer screening in society and space
}

\author{
Krzysztof Czaderny ${ }^{1, A-F}$ \\ ${ }^{1}$ Maria Skłodowska-Curie Institute - Oncology Centre, Warsaw School of Economics, Warsaw, Poland \\ A - Research concept and design, B - Collection and/or assembly of data, C - Data analysis and interpretation, \\ $D$ - Writing the article, $E$ - Critical revision of the article, F - Final approval of article
}

Czaderny K. Increasing deaths from colorectal cancer in Poland - Insights for optimising colorectal cancer screening in society and space. Ann Agric Environ Med. 2019; 26(1): 125-132. doi: 10.26444/aaem/99233

\begin{abstract}
Introduction and objective. With respect to the increasing numbers of deaths due to colorectal cancer in Poland, the aim of the study was to investigate socio-demographic characteristics which influence colorectal cancer screening acceptance and to assess spatial variation of colorectal cancer mortality.

Materials and method. An age-period-cohort model was estimated to assess mortality trends in colorectal cancer in Poland. A geographical analysis was performed by spatial regression. Factors influencing participation in colorectal cancer screening were identified using structural equation modelling.

Results. In 2014 in Poland, 6.4 thousand men and 5.0 thousand women died due to colorectal cancer. In total, by 2030 this number is expected to rise to nearly 14.4 thousand. Observed spatial clustering of age-adjusted colorectal cancer mortality is associated with spatial variation in tobacco use, employment in industry, and consumption of red meat. Patientphysician communication, advanced age, and healthy diet are the most important predictors of colorectal cancer screening acceptance. Tobacco and alcohol users are not more likely to participate in colorectal cancer screening, adjusting for other variables.

Conclusions. Self-selection of patients who follow healthy diet means that individuals at higher risk of colorectal cancer are less likely to participate in colorectal cancer screening. Therefore, screening should be more targeted. According to the structural equation modelling results, the phenomenon of 'no-show' for screening can be mitigated by patient-physician communication. The inhabitants of the Greater Poland region are at the highest risk of dying due to colorectal cancer, which may have public health policy implications.
\end{abstract}

\section{Key words}

colorectal neoplasms, mortality, colonoscopy, mass screening, screening acceptance, self-selection

\section{INTRODUCTION}

The number of deaths from colorectal cancer (ICD-10: C18-C21, ICD-9: 153-154) has been increasing in Poland since the 1980s. Colorectal cancer screening programmes are running in most EU countries. European guidelines for quality assurance in colorectal cancer screening and diagnosis were issued by the European Commission in 2010. The target population refers to men and women aged 50-74 years. The invitation-reminder system aims to give each eligible individual an equal chance of benefiting from screening. To identify what socio-demographic factors influence participation in colorectal cancer screening, a structural equation model was estimated. A hypothesis of self-selection of participants at lower risk of colorectal cancer was examined.

Most colorectal cancer prevention programmes are implemented at the country level; however, mortality and incidence of colorectal cancer vary with geography, as will be shown later. In this study, the main determinants of spatial clustering of colorectal cancer mortality in Poland were

Address for correspondence: Krzysztof Czaderny, Institute of Statistics and Demography; Warsaw School of Economics, Madalińskiego 6/8, 02-513 Warsaw, Poland

e-mail: krzysztof.czaderny@coi.pl

Received: 30.09.2018; accepted: 26.10.2018; first published: 10.12.2018 examined by spatial lag model. In prior research, the risk of developing colorectal cancer was found to be associated with smoking tobacco, being overweight or obese, drinking excessive alcohol, consuming processed and red meat, having a family history of colorectal cancer, and having inflammatory bowel disease [1].

\section{OBJECTIVE}

This article is aimed at the identification of hard-to-reach groups and the detection of spatial clusters of elevated cancer risk, with respect to the increasing numbers of deaths due to colorectal cancer in Poland. Both tasks were shown to be useful tools for optimising colorectal cancer screening $[2,3]$. Spatial clusters should form geographic targets for colorectal cancer screening interventions. The identification of hardto-reach groups for screening is the first step in improving participation and coverage rates.

\section{MATERIALS AND METHOD}

Age-Period-Cohort Model. According to the age-periodcohort model, hazard rate of mortality, $\lambda_{i j}$, at age $i$ and in year $j$ is given by $[4,5]$ : 


$$
\log \lambda_{i j}=a_{i}+p_{j}+c_{j-i}, \quad i=1, \ldots, n_{a}, j=1, \ldots, n_{c}
$$

where $a$ describes the age effect, $p$ the year effect, and $c$ the cohort effect. Perfect collinearity between variables of age, period, and cohort presents a methodological challenge and standard regression techniques cannot be applied. To achieve identifiability, parameters must respect the particular constraints employed. Most common mortality models can be estimated using the language of generalised linear or nonlinear models [6]. The R package StMoMo provides tools for fitting stochastic mortality models, including the age-periodcohort model, Lee-Carter model, Renshaw-Haberman model, and Cairns-Blake-Dowd model [7]. Among these, the specification of the age-period-cohort model was chosen based on Akaike's and Bayesian information criteria. In the forecast one assumed that the cohort index follows an ARIMA $(1,1,0)$ process with drift. For the period index, the random walk process with drift was assumed. These assumptions are in line with the previous research on forecasting using parametric mortality models $[7,8]$.

Prediction of number of colorectal cancer deaths up to 2035 has been based on the historical trends of mortality in Poland in 1980-2014 and the demographical prognosis made by the Polish Central Statistical Office [9]. Mortality rates were standardised to the 2014 Polish census population. Mortality data comes from the Polish National Cancer Registry and was obtained from death certificates collected by the Polish Central Statistical Office.

Spatial Model. Spatial clusters were identified by Kulldorff's scan statistic [10]. Kulldorff's approach tests the hypothesis that there is an elevated risk within a window centred at some point compared with outside it. Since the distribution of test statistic is not determined, Monte Carlo simulation was used to perform the hypothesis test ( $N_{\text {rep }}=9,999$ replicates). The rank of the likelihood ratio among all randomisation tests determines the $P$-value. The most likely cluster is the window which attains the maximum likelihood value. Secondary clusters have significantly large likelihood ratio, but less than the most likely one. Clustering hypothesis was tested at $\alpha=0.001$ level of significance using data from the 2010-2014 and, for comparison, the 1980-1984 period.

Causes of spatial clustering of colorectal cancer mortality were identified using a spatial regression model. A problem of endogeneity emerges in that the spatially lagged dependent variable is correlated with the stochastic disturbance. Lagged endogenous variable is used to incorporate spatial autocorrelation and to capture the effects of omitted variables. Spatial lag model allows assessment of the degree of spatial dependence and significance of other (aspatial) predictor variables [11]:

$$
y=\rho \boldsymbol{W} y+X \beta+\varepsilon, \quad|\rho|<1,
$$

where $\rho$ is the spatial autoregressive coefficient, $y$ is endogenous variable (age-adjusted colorectal cancer mortality rate), $\boldsymbol{X}$ is matrix of exogenous variables, and $\boldsymbol{W}$ is the spatial weights matrix.

Dietary data used in the regression as exogenous variables are based on the Target Group Index survey conducted on a quota random sample of $N=251,688$ Polish residents in the 2001-2007 period. Its sample is representative for the population aged 15-75. A mixed mode design was used, where respondents were approached by computer-assisted personal interviewing, paper-based personal interviewing, and computer-assisted web interviewing. Data were aggregated to produce county estimates. Data on industry employment, registered unemployment, number of outpatient departments, wages, and salaries by county were obtained from the Polish Central Statistical Office.

Structural Equation Model. Factors influencing participation in colorectal cancer screening (manifested by having a colonoscopy or having a faecal occult blood test) were identified using a structural equation model. This was fitted using weighted least squares means and variance adjusted (WLSMV) estimation [12]. The WLSMV estimator is an appropriate choice for models including categorical indicators. Latent variables included in the model are listed in Table 1. Internal consistency was investigated for all reflective measurement models. The proposed measurement scales demonstrated high levels of reliability with McDonald's omega [13] ranging from $\omega=0.695$ to $\omega=0.922$. The estimated structural equation model also included a single-item variable of age $\left(a_{1}\right)$.

Goodness of fit of the structural equation model was assessed by root mean square error of approximation (RMSEA), comparative fit index (CFI), and Tucker-Lewis Index (TLI). RMSEA is an absolute fit index, whereas CFI and TLI are relative fit indices. According to conventional criteria, RMSEA values below 0.05 and CFI, TLI values of 0.95 or higher indicate a good fit of the model $[14,15]$.

This part of the analysis was based on nationally representative data from the 2014 survey Awareness of Cancer and its Prevention, which was carried out on a stratified random sample of $N=8,000$ adults living in Poland. The survey was conducted by computer-assisted personal interviewing during the second half of 2014. The survey was contracted by the Maria Skłodowska-Curie Institute - Oncology Centre and financed by the Ministry of Health of Poland within the National Programme for Combating Cancer. The survey questions were focused on awareness of prevention advice of the European Code Against Cancer. For the structural equation model presented further, the investigation was limited to a subsample of men and women older than 40 years $(N=4,500)$. The WLSMV estimator provided a good approximation and reliable estimates for this sample size [16].

\section{RESULTS}

Colorectal Cancer Mortality. In 2014 in Poland, 6.4 thousand men and 5.0 thousand women died due to colorectal cancer. The upward trend in the number of deaths from colorectal cancer is expected to continue until the 2030s (Fig. 1). The male-to-female gap in colorectal cancer mortality rate has widened since the 1980s. In 2010-2014, the male-to-female mortality ratio was $1.29-1.38$. In the 2020 s, this ratio is expected to exceed 1.40 each year.

The increasing number of deaths from colorectal cancer can be illustrated by maps (Fig. 2). Spatial distribution of colorectal cancer mortality has changed considerably in the last three decades. In 1980-1984, the primary clusters of male and female mortality due to colorectal cancer were placed in the central-southern Poland (Upper Silesia). These clusters were centred in the Siemianowice City (male population, 
Table 1. Reflective, formative and manifest variables included in the structural equation model

\begin{tabular}{|c|c|c|c|}
\hline Latent variable & Observed measures of latent variables & Data type of observed variables & Scale reliability (McDonald's omega) \\
\hline $\begin{array}{l}\text { Participation in } \\
\text { colorectal cancer } \\
\text { screening }\left(\eta_{1}\right)\end{array}$ & $\begin{array}{l}y_{1}-\text { Have you ever had a colonoscopy? What was the reason for your last } \\
\text { colonoscopy? } \\
y_{2}-\text { Have you ever had a blood stool test? What was the reason for your } \\
\text { last blood stool test? }\end{array}$ & $\begin{array}{l}\text { Responses were coded as } 1 \\
\text { if the respondent had a } \\
\text { preventive measures (without } \\
\text { symptoms observed) and } 0 \\
\text { otherwise. }\end{array}$ & Formative measurement model. \\
\hline $\begin{array}{l}\text { Knowledge of } \\
\text { colorectal cancer } \\
\left(\eta_{2}\right)\end{array}$ & $\begin{array}{l}y_{3}-\text { Can the following lifestyle changes lower the colorectal cancer risk? } \\
\text { Eating more fruits and vegetables. } \\
y_{4}-\text { Can the following lifestyle changes lower the colorectal cancer risk? } \\
\text { Avoiding fatty foods. } \\
y_{5}-\text { Can the following lifestyle changes lower the colorectal cancer } \\
\text { risk? Eating more food such as buckwheat, barley groats, pearl barley, } \\
\text { oatmeal, brown bread. } \\
y_{6}-\text { Can the following lifestyle changes lower the colorectal cancer risk? } \\
\text { More physical activity, including walking and gymnastics. }\end{array}$ & Three-category variables. & $\begin{array}{l}\text { Reflective measurement model: } \\
0.885 \text { ( } 95 \% \mathrm{Cl} \text { using percentile } \\
\text { bootstrap: } 0.876-0.893)\end{array}$ \\
\hline Healthy diet $\left(\eta_{3}\right)$ & $\begin{array}{l}y_{7}-\text { How often do you eat vegetables, excluding potatoes, chips? } \\
y_{8}-\text { How often do you eat fruits? } \\
y_{9}-\text { Do you eat reasonably healthy meals and avoid overeating? }\end{array}$ & $\begin{array}{l}\text { Two six-category variables }\left(y_{7}-\right. \\
\left.y_{8}\right) \text { and a binary item }\left(y_{9}\right)\end{array}$ & $\begin{array}{l}\text { Reflective measurement model: } \\
0.716 \text { ( } 95 \% \mathrm{Cl}: 0.698-0.736)\end{array}$ \\
\hline $\begin{array}{l}\text { Addictive } \\
\text { behaviours }\left(\eta_{4}\right)\end{array}$ & $\begin{array}{l}y_{10} \text { - Do you smoke tobacco? How many factory-made cigarettes, hand- } \\
\text { rolled cigarettes, cigars, tobacco pipes do you smoke a day? } \\
y_{11} \text { - How often have you drunk alcohol in the last year? } \\
y_{12} \text { - How many servings of alcohol do you drink a day, when you drink } \\
\text { alcohol? }\end{array}$ & $\begin{array}{l}\text { Two continuous variables }\left(y_{10^{\prime}}\right. \\
\left.y_{12}\right) \text { and a five-category item } \\
\left(y_{11}\right) \text {. }\end{array}$ & $\begin{array}{l}\text { Reflective measurement model: } \\
0.695 \text { ( } 95 \% \mathrm{Cl}: 0.676-0.715)\end{array}$ \\
\hline Physical activity $\left(\eta_{5}\right)$ & $\begin{array}{l}y_{13} \text { - Do you perform intensive physical activity, including: jogging, } \\
\text { swimming, aerobics, cycling. How much time do you spend on it in a } \\
\text { typical week? } \\
y_{14} \text { - Do you perform intensive physical training, including: gymnasium, } \\
\text { practice of sport. How much time do you spend on it in a typical week? }\end{array}$ & Continuous variables. & $\begin{array}{l}\text { Reflective measurement model: } \\
0.922 \text { ( } 95 \% \mathrm{Cl}: 0.905-0.936)\end{array}$ \\
\hline $\begin{array}{l}\text { Physician's passivity } \\
\left(\xi_{1}\right)\end{array}$ & $\begin{array}{l}x_{1}-\text { I do not have preventive blood tests, because a doctor does not } \\
\text { order it. } \\
x_{2}-\text { I do not do preventive urine tests, because a doctor does not order it. } \\
x_{3}-\text { I do not do preventive cholesterol tests, because a doctor does not } \\
\text { order it. } \\
x_{4}-\text { I do not do preventive blood sugar tests, because a doctor does not } \\
\text { order it. } \\
x_{5}-\text { I do not measure blood pressure for preventing diseases, because a } \\
\text { doctor does not recommend it. }\end{array}$ & Binary variables. & $\begin{array}{l}\text { Reflective measurement model: } \\
0.892 \text { (95\% Cl: } 0.882-0.903)\end{array}$ \\
\hline $\begin{array}{l}\text { Local availability of } \\
\text { healthcare }\left(\xi_{2}\right)\end{array}$ & $\begin{array}{l}x_{6}-\text { Number of appointments with a family doctor per capita in the } \\
\text { commune (gmina) where the respondent lives. } \\
x_{7}-\text { Number of appointments with a specialised doctor per capita in the } \\
\text { commune (gmina) where the respondent lives. } \\
x_{8}-\text { Number of clinics per } 10,000 \text { residents in the district (powiat) where } \\
\text { the respondent lives. } \\
x_{9}-\text { Number of appointments with any doctor per capita in the district } \\
\text { (powiat) where the respondent lives. }\end{array}$ & Continuous variables. & $\begin{array}{l}\text { Reflective measurement model: } \\
0.869 \text { ( } 95 \% \mathrm{Cl}: 0.860-0.876)\end{array}$ \\
\hline $\begin{array}{l}\text { Socio-economic } \\
\text { status }\left(\xi_{3}\right)\end{array}$ & $\begin{array}{l}x_{10}-\text { Please rate living conditions of your household in general. } \\
x_{11}-\text { What level of education have you completed? }\end{array}$ & $\begin{array}{l}\text { A five-category item }\left(x_{10}\right) \text { and } \\
\text { a three-category item }\left(x_{11}\right) \text {. }\end{array}$ & Formative measurement model. \\
\hline
\end{tabular}

$\log$ likelihood ratio: $\log \lambda=84.69, p=0.001)$ and Pszczyński County (female population, $\log$ likelihood ratio: $\log \lambda=62.74$, $p=0.001$ ). Probability value of $p=0.001$ for detected spatial clusters means, the observed rank of the log-likelihood ratio statistic is 1, using Monte Carlo testing with 999 replicates. Therefore, it is extremely unlikely that the elevated mortality in specified areas in 1980-1984 was a result of random processes. However, spatial autocorrelation of colorectal cancer mortality across the country was relatively low in both periods and both genders, which is demonstrated by global Moran's statistic $\left(I_{\text {men,1980-1984 }}=0.256, I_{\text {men,2010-2014 }}=0.251\right.$ and $\left.I_{\text {women, } 1980-1984}=0.246, I_{\text {women, } 2010-2014}=0.310\right)$.

The Upper-Silesian cluster of elevated colorectal cancer mortality did not disappear in 2010-2014; however, the cluster of elevated colorectal cancer mortality in Upper Silesia has become smaller and less statistically significant, both in males $(\log \lambda=26.65, p=0.002)$ and females $(\log \lambda=18.13$, $p=0.001)$. This can be considered a secondary cluster in
2010-2014. For the 2010-2014 period, test statistics were greater for clusters situated in Greater Poland. The centre of this cluster was situated in the city of Śrem for the male population $(\log \lambda=26.6, p=0.001)$ and in Obornicki County for the female population $(\log \lambda=25.7, p=0.001)$. Clusters of elevated mortality for both genders were placed close together, which means that spatial distribution of risk factors was similar for both genders.

Factors Influencing Spatial Variation in Colorectal Cancer Mortality. Tobacco use is the most important factor for spatial variation of age-adjusted colorectal cancer mortality in Poland (Tab. 2). The proportion of tobacco smokers is higher in northern and western Poland. A spatial relationship between employment in industry and colorectal cancer has been established. This finding is consistent with the location of the spatial cluster in Upper Silesia, both in the 1980-1984 and 2010-2014 periods. Geographical differences in red 
a) males

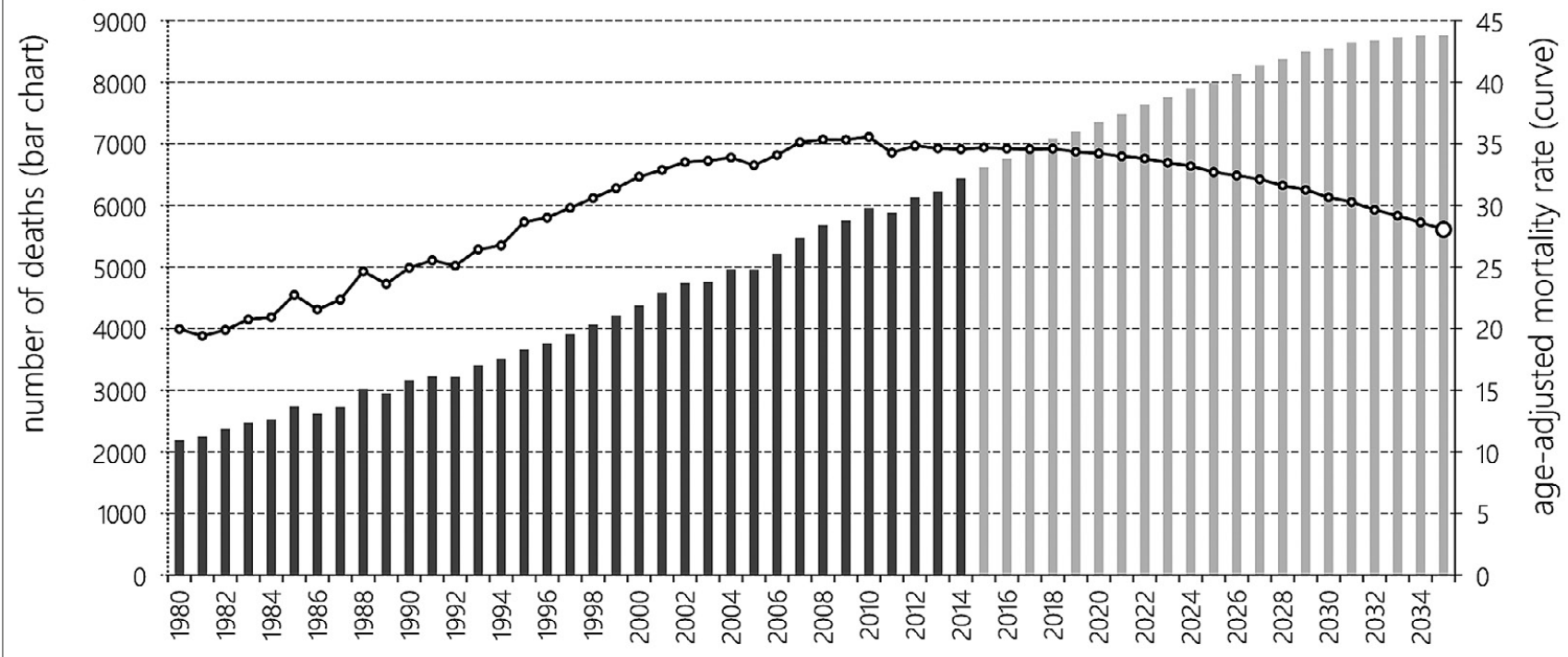

b) females

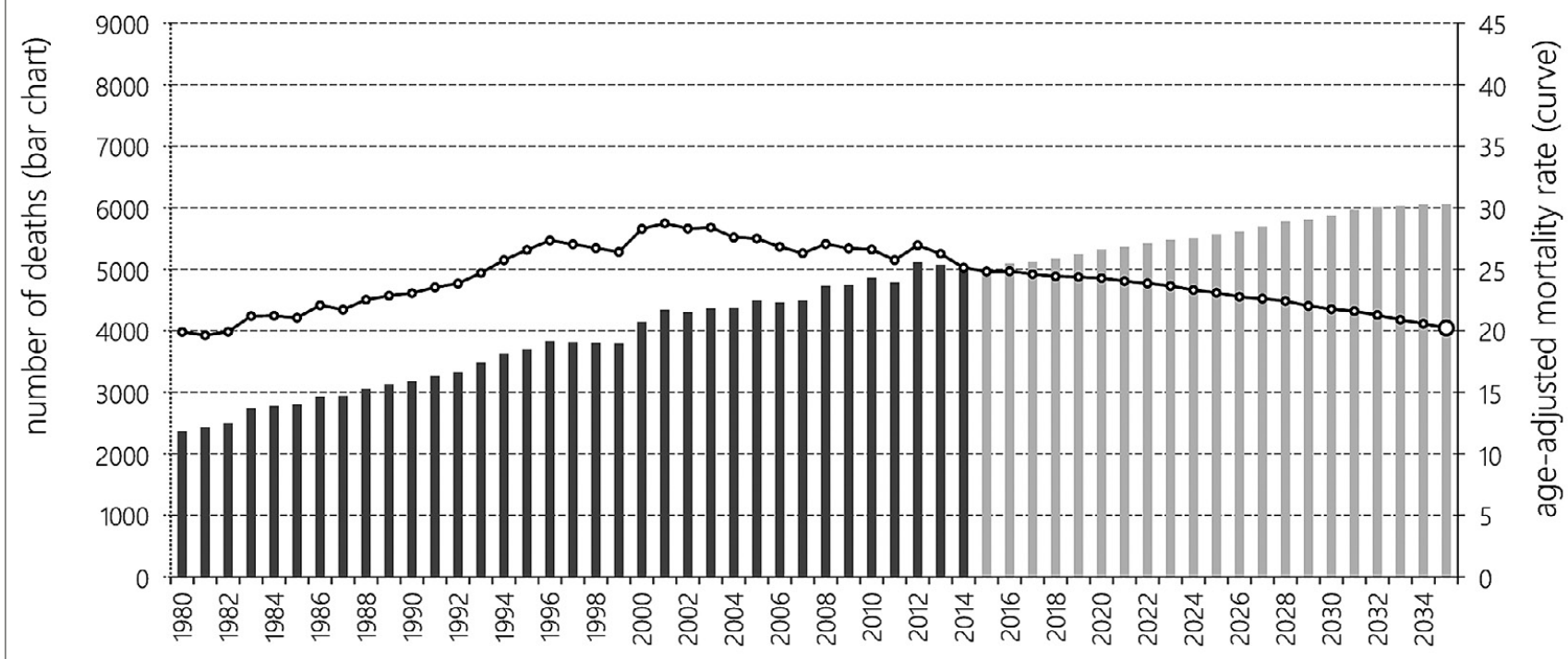

$\square$ number of deaths

$\rightarrow$ mortality (per 100,000 females)

Figure 1. Colorectal cancer deaths and age-adjusted mortality rate in Poland. Registry data for 1980-2014 and forecast until 2035

meat consumption are another highly likely reason for the spatial clustering of colorectal cancer mortality in Poland. The model identifies a possible association between fish consumption and colorectal cancer, hypothesising also a protective role of fish in colorectal cancer. Mortality rates of colorectal cancer are slightly higher in counties with a higher obesity rate $(B M I \geq 30)$ according to the spatial lag model. However, both latter variables demonstrate $\mathrm{p}$-values far greater than 0.05. Similar results were obtained after adjusting for socio-economic background (Tab. 2, column B). Data on other risk factors for colorectal cancer [1] are not available at the county level. As noted, the spatial lag model captures the effects of omitted variables, which is often the case in spatial epidemiology.
Factors Influencing Participation in Colorectal Cancer Screening. The structural equation model was built using previously validated constructs, which are discussed in the methodological part of the study. For the postulated model, all the goodness-of-fit indices met the cut-off criteria $(R M S E A=0.039, C F I=0.973, T L I=0.969)$. The eight unobservable (latent) indicators are represented by ovals (Fig. 3). The arrows between indicators represent regression paths. The direct effects are causal pathways between variables while controlling for mediators. The total effect is a sum of direct and indirect effects. The double-headed arrows represent covariances.

Structural equation modelling analysis found statistically significant direct effects of variables of physician's passivity, 


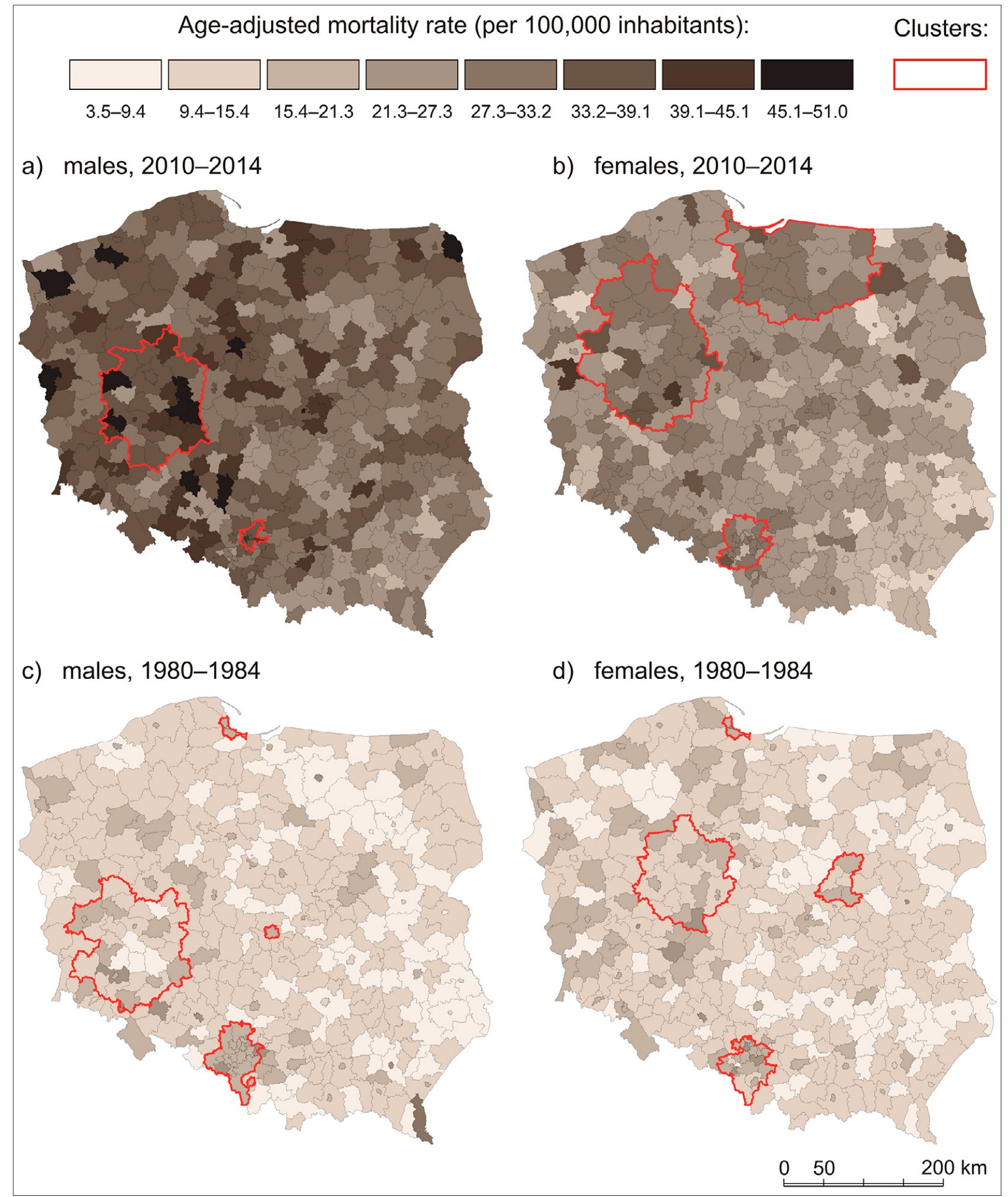

Figure 2. Spatial distribution of age-adjusted colorectal cancer mortality in Poland. Clusters identified by the Kulldorff's scan statistic

age, and healthy diet on participation in colorectal cancer screening (Tab. 3). The total effects of knowledge of socioeconomic status, knowledge of colorectal cancer, and local availability of healthcare on participation in colorectal cancer screening tests are much lower and, at least in part, indirect. Tobacco and alcohol users are not likely to self-select themselves for colorectal cancer screening, adjusting for other variables. The latent variable of addictive behaviours is not significantly related to colorectal cancer screening acceptance.

The results shown in Tab. 4 suggest that patient-physician communication, socio-economic status, and local availability of healthcare are strongly associated with knowledge of colorectal cancer. As discussed previously, participation rates 
Table 2. Spatial lag model of age-adjusted lung cancer mortality: $[\mathrm{A}]-$ epidemiological model; [B] - epidemiological-economic model (with the inclusion of socio-economic controls). Estimation results for 380 counties

\begin{tabular}{|c|c|c|c|c|}
\hline & \multicolumn{2}{|c|}{$[\mathrm{A}]$} & \multicolumn{2}{|c|}{$[\mathrm{B}]$} \\
\hline & estimate & $p$-value & estimate & $p$-value \\
\hline Spatial lag $(\rho)$ & 0.31521 & $<0.00001$ & 0.312145 & $<0.00001$ \\
\hline Constant & 0.00032 & 0.00594 & 0.00048 & 0.00078 \\
\hline Share of daily smokers (\%) & 0.00165 & $<0.00001$ & 0.00174 & $<0.00001$ \\
\hline $\begin{array}{l}\text { Employment in industry (\% } \\
\text { of total employment) }\end{array}$ & 0.00025 & 0.02331 & 0.00027 & 0.01854 \\
\hline $\begin{array}{l}\text { Per-capita red meat } \\
\text { consumption (Kg/month) }\end{array}$ & 0.00004 & 0.06333 & 0.00004 & 0.07133 \\
\hline $\begin{array}{l}\text { Per-capita fish consumption } \\
\text { (Kg/month) }\end{array}$ & -0.00028 & 0.23404 & -0.00023 & 0.34015 \\
\hline Obesity rate (\%) & 0.00055 & 0.25674 & 0.00060 & 0.21897 \\
\hline $\begin{array}{l}\text { Average monthly gross } \\
\text { wages and salaries (PLN) }\end{array}$ & * & * & $<0.00001$ & 0.04802 \\
\hline $\begin{array}{l}\text { Registered unemployment } \\
\text { rate (\%) }\end{array}$ & * & * & $<0.00001$ & 0.38974 \\
\hline $\begin{array}{l}\text { Out-patient departments } \\
\text { (No. per } 10,000 \text { population) }\end{array}$ & * & * & $<0.00001$ & 0.22394 \\
\hline
\end{tabular}

are likely to increase with age, adjusting for other variables included in the model. However, the level of knowledge regarding risk factors of colorectal is not age dependent, adjusting for other factors. Socio-economic status has a direct positive effect both on participation in colorectal cancer screening and knowledge of colorectal cancer. However, the effect of socio-economic status on the latter variable only is highly statistically significant.
Table 3. Standardised direct, indirect and total effects on participation in colorectal cancer screening $\left(\eta_{1}\right)$

\begin{tabular}{lcccccc}
\hline & \multicolumn{2}{c}{ Total effect } & \multicolumn{2}{c}{ Direct effect } & \multicolumn{2}{c}{ Indirect effect } \\
\cline { 2 - 7 } & estimate & $p$-value & estimate & $p$-value & estimate & $p$-value \\
\hline $\begin{array}{l}\text { Physician's passivity } \\
\left(\xi_{1}\right)\end{array}$ & -0.667 & $<0.001$ & -0.549 & 0.001 & -0.118 & 0.001 \\
\hline Age $\left(a_{1}\right)$ & 0.585 & $<0.001$ & 0.585 & $<0.001$ & - & - \\
\hline Healthy diet $\left(\eta_{3}\right)$ & 0.534 & 0.001 & 0.534 & 0.001 & - & - \\
\hline $\begin{array}{l}\text { Socio-economic } \\
\text { status }\left(\xi_{3}\right)\end{array}$ & 0.272 & 0.047 & 0.208 & 0.126 & 0.065 & 0.003 \\
\hline $\begin{array}{l}\text { Knowledge of } \\
\text { colorectal cancer }\left(\eta_{2}\right)\end{array}$ & 0.134 & 0.001 & - & - & 0.134 & 0.001 \\
\hline $\begin{array}{l}\text { Local availability of } \\
\text { healthcare }\left(\xi_{2}\right)\end{array}$ & 0.011 & 0.010 & - & - & 0.011 & 0.010 \\
\hline
\end{tabular}

Table 4. Standardised direct, indirect and total effects on knowledge of colorectal cancer $\left(\eta_{2}\right)$

\begin{tabular}{lllllll}
\hline & \multicolumn{2}{c}{ Total effect } & \multicolumn{2}{c}{ Direct effect } & \multicolumn{2}{c}{ Indirect effect } \\
\cline { 2 - 7 } & estimate & $p$-value & estimate & $p$-value & estimate & $p$-value \\
\hline $\begin{array}{l}\text { Physician's passivity } \\
\left(\xi_{1}\right)\end{array}$ & -0.221 & $<0.001$ & -0.221 & $<0.001$ & - & - \\
\hline $\begin{array}{l}\text { Socio-economic } \\
\text { status }\left(\xi_{3}\right)\end{array}$ & 0.101 & $<0.001$ & 0.101 & $<0.001$ & - & - \\
\hline $\begin{array}{l}\text { Local availability of } \\
\text { healthcare }\left(\xi_{2}\right)\end{array}$ & 0.085 & $<0.001$ & 0.085 & $<0.001$ & - & - \\
\hline
\end{tabular}

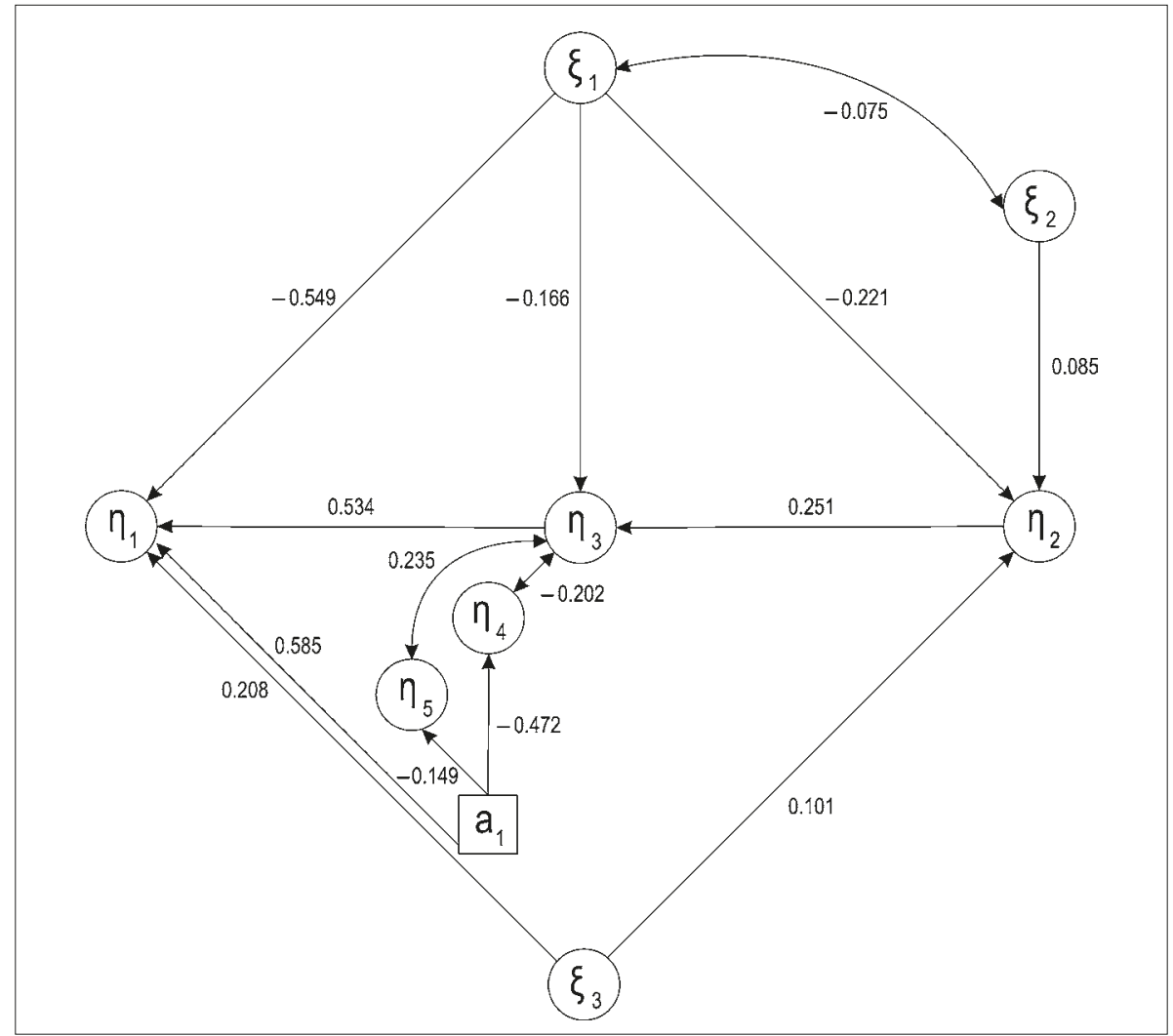

Figure 3. Path diagram of structural equation model - structural part 


\section{DISCUSSION}

In Poland, age-adjusted mortality of colorectal cancer is expected to continue to fall in the next two decades. This trend started in the early 2000s in the female population and in the 2010s in the male population. Decreasing age-adjusted mortality is observed (particularly in women) also in other Central European countries, including the Czech Republic, Hungary, and Slovakia [17]. However, owing to demographic trends, the total number of deaths due to colorectal cancer is expected to increase. This highlights the need for increased attention to and efforts for optimising colorectal cancer screening.

Participation in colorectal cancer is spatially differentiated and varies among programmes. A colonoscopy has been introduced, either as the only method of screening (as in Poland) or the method of choice [18]. In 2015 in Poland, the participation rate in colorectal cancer screening amounted to $17 \%$. The Netherlands showed the highest participation rates worldwide (68\%), followed by Denmark (65\%) [19]. Participation in colorectal cancer screening is voluntary and, therefore, a self-selection of patients at lower risk for colorectal cancer can be observed, as shown by the model.

Most of the previous evaluations of the factors and strategies of uptake in colorectal cancer screening for the hard-to-reach population have focused on socio-economic status and socio-economic deprivation. Far fewer studies have investigated the association between participation in colorectal cancer screening and knowledge, attitudes, beliefs, health-related behaviours [20]. There was no consistent pattern for all variables measured in more than one study with the exception of perceived susceptibility. However, most previous studies found a positive univariate association of adherence to faecal occult blood testing and physician advice, health orientation, and knowledge of cancer risk factors [20]. In prior research, the association between diet and colorectal cancer acceptance was rarely examined. Results of the structural equation model provide evidence of positive self-selection in colorectal cancer screening, making the intervention less effective. Using the same data and method, the importance of individual factors (including following healthy diet) on prostate cancer screening uptake could not be found [21].

In the English National Health Service (NHS) colorectal cancer screening programme, the proportion screened is higher in older individuals and decreases with area deprivation [22]. According to a large-sample study conducted in Scotland in 1996-1998, socio-economic deprivation is a factor decreasing the probability of returning a screening questionnaire, expression of interest in screening, and attendance at screening [23]. In Denmark, the highest participation rate is observed in the highest income quartile and those aged 66-70 [24]. In Poland, individuals at old age and of high socio-economic status are also more likely to participate in colorectal cancer screening (Tab. 3).

The detected spatial clusters of colorectal cancer mortality constitute priority areas for screening intervention. In the current study, ecological inference was used to confirm the non-randomness of spatial distributions (given by likelihood ratios) rather than to reconstruct individual associations from group-level data. Geographical distribution of colorectal cancer mortality and incidence in many world regions has been examined to date $[25,26]$. Colorectal cancer mortality was found to be higher in high-income countries [27], which is consistent with the interrelation between colorectal cancer mortality and salaries and wages observed in Poland (Tab. 2). Tobacco use is the most significant factor of spatial variation of colorectal cancer mortality according to the postulated spatial lag model. Two more covariates appeared to be statistically important at the 0.10 level: employment in industry and red meat consumption. The link between cigarette smoking and colorectal cancer risk was controversial; however, it was proved that relative to nonsmokers, current and former smokers have a significantly increased risk of colorectal cancer incidence and mortality [28]. An inverse relationship between fish consumption and colorectal cancer was found in most previous studies [29], whereas the relationship between red meat consumption and colorectal cancer remains a subject of scientific debate. This association is possibly weak in magnitude and heterogeneous across the subgroup analyses [30]. Obesity is linked with an increased risk of colon cancer in men; however, the association is less consistent in women [31].

Some limitations to the performed ecological regression (spatial lag model) should be noted. First, the analysed data on consumption and health behaviours are not available for the period prior to 2001. Intergenerational transmission of dietary behaviours in Poland has not been analysed. Second, factors for spatial variation of cancer mortality may differ from factors for developing cancer. Third, some characteristics have a low spatial variation (e.g. $C V=13 \%$ for red meat consumption, compared to $C V=42 \%$ for employment in industry). The data are retrospective and self-reported.

In prior research, certain occupations and occupational exposures have been linked to the risk of colorectal cancer. This relationship varies between branches. Elevated risks of colorectal cancer were identified for labourers occupied in industries with a wide use of chemical compounds, basic metals, plastic, rubber and asbestos [32]. Upper Silesia was once the centre of heavy industry of Poland, but during the last 30 years a distinct decrease in employment in industry in Upper Silesia region and the reduction in the clustering of colorectal cancer mortality in this region (measured by likelihood ratio), has taken place, as discussed previously. Due to Poland's economic transition from planned economy to market economy, during the 1990s industry in the country was modernised and declined considerably.

\section{CONCLUSIONS}

The upward trend in colorectal cancer deaths is expected to continue until the 2030s. A non-random pattern in the spatial distribution of colorectal cancer mortality was found. Spatial clustering is determined mostly by tobacco use differences. The inhabitants of the Greater Poland region are of the highest risk of dying due to colorectal cancer. The structural equation model indicated the existence of self-selection in participation in colorectal cancer screening. Individuals who follow a healthy diet are much more likely to undergo colorectal cancer screening. This means that individuals with lower risk of colorectal cancer due to following a healthy diet are more likely to participate in colorectal cancer screening. Addictive behaviours are not related to colorectal cancer screening acceptance, adjusting for other variables. Patient- 
physician communication is the most important factor of patients' knowledge of colorectal cancer. Reducing the size of the self-selection could make screening more cost-effective.

\section{Acknowledgment}

This work was supported by the Maria Skłodowska-Curie Institute - Oncology Centre (grant no. GW35KC).

\section{REFERENCES}

1. Johnson CM, Wei C, Ensor JE, Smolenski DJ, Amos CI, Levin B, et al. Meta-analyses of colorectal cancer risk factors. Cancer Causes Control. 2013; 24(6): 1207-1222.

2. Sherman RL, Henry KA, Tannenbaum SL, Feaster DJ, Kobetz E, Lee DJ. Applying spatial analysis tools in public health: an example using SaTScan to detect geographic targets for colorectal cancer screening interventions. Prev Chronic Dis. 2014; 11: E41.

3. Huang JL, Fang Y, Liang M, Li ST, Ng SK, Hui ZS, et al. Approaching the hard-to-reach in organized colorectal cancer screening: an overview of individual, provider and system level coping strategies. AIMS Public Health. 2017; 4(3): 289-300.

4. Clayton D, Schifflers E. Models for temporal variation in cancer rates. II: Age-period-cohort models. Stat Med. 1987; 6(4): 469-481.

5. Hobcraft J, Menken J, Preston S. Age, period, and cohort effects in demography: a review. Popul Index. 1982; 48(1): 4-43.

6. Currie ID. On fitting generalized linear and non-linear models of mortality. Scand Actuar J. 2016; 2016(4): 356-383.

7. Villegas AM, Millossovich P, Kaishev VK. StMoMo: An R package for stochastic mortality modelling. R package 2017. Accessed August 1st 2018 at: https://CRAN.R-project.org/package $=$ StMoMo.

8. Haberman S, Renshaw A. On age-period-cohort parametric mortality rate projections. Insur Math Econ. 2009; 45(2): 255-270.

9. Central Statistical Office of Poland. Population projection 2014-2050. Warsaw, 2014

10. Kulldorff M, Nagarwalla N. Spatial disease clusters: detection and inference. Stat Med. 1995; 14(8): 799-810.

11. Anselin L. Spatial econometrics: Methods and models. 1st ed. Dordrecht: Kluwer Academic Publishers, 1988.

12. Muthén B, Du Toit SHC, Spisic D. Robust inference using weighted least squares and quadratic estimating equations in latent variable modeling with categorical and continuous outcomes, 1997. Accessed August 1st, 2018 at: http://www.statmodel.com/download/Article_075.pdf.

13. McDonald RP. Test theory: A unified treatment. Mahwah, NJ: Lawrence Erlbaum, 1999.

14. Browne MW, Cudeck R. Alternative ways of assessing model fit. In: Bollen KA, Long JS, editors. Testing structural equation models. Vol. 154. Newbury Park: Sage, 1993: 136-162.

15. Hu LT, Bentler PM. Cutoff criteria for fit indexes in covariance structure analysis: Conventional criteria versus new alternatives. Struct Equ Modeling. 1999; 6(1): 1-55.
16. Nussbeck F, Eid M, Lischetzke T. Analysing multitrait-multimethod data with structural equation models for ordinal variables applying the WLSMV estimator: What sample size is needed for valid results? Br J Math Stat Psychol. 2006; 59(Pt 1): 195-213.

17. Bosetti C, Levi F, Rosato V, Bertuccio P, Lucchini F, Negri E, et al. Recent trends in colorectal cancer mortality in Europe. Int J Cancer. 2011; 129(1): 180-191.

18. Zavoral M, Suchanek S, Zavada F, Dusek L, Muzik J, Seifert B, et al. Colorectal cancer screening in Europe. World J Gastroenterol. 2009; 15(47): 5907-5915.

19. Navarro M, Nicolas A, Ferrandez A, Lanas A. Colorectal cancer population screening programs worldwide in 2016: An update. World J Gastroenterol. 2017; 23(20): 3632-3642.

20. Vernon SW. Participation in colorectal cancer screening: a review. J Natl Cancer Inst. 1997; 89(19): 1406-1422.

21. Czaderny K. High prostate cancer mortality in Poland. A spatial, temporal and structural analysis. Przegl Epidemiol. 2018; 72(2): 235246.

22. McGregor LM, von Wagner C, Atkin W, Kralj-Hans I, Halloran SP, Handley $\mathrm{G}$ et al. Reducing the social gradient in uptake of the NHS Colorectal Cancer Screening Programme using a narrative-based information leaflet: A cluster-randomised trial. Gastroenterol Res Pract. 2016; 2016: 3670150.

23. Arnold M, Sierra MS, Laversanne M, Soerjomataram I, Jemal A, Bray F. Global patterns and trends in colorectal cancer incidence and mortality. Gut. 2017; 66(4): 683-691.

24. McCaffery K, Wardle J, Nadel M, Atkin W. Socioeconomic variation in participation in colorectal cancer screening. J Med Screen. 2002; 9(3): 104-108

25. Deding U, Henig AS, Salling A, Torp-Pedersen C, Bøggild H. Sociodemographic predictors of participation in colorectal cancer screening. J Colorectal Dis. 2017; 32(8): 1117-1124.

26. Khosravi Shadmani F, Ayubi E, Khazaei S, Sani M, Mansouri Hanis S, Khazaei S, et al. Geographic distribution of the incidence of colorectal cancer in Iran: a population-based study. Epidemiol Health. 2017; 39: e2017020.

27. Lai SM, Zhang KB, Uhler RJ, Harrison JN, Clutter GG, Williams MA. Geographic variation in the incidence of colorectal cancer in the United States, 1998-2001. Cancer. 2006; 107 (5 Suppl): 1172-1180.

28. Liang PS, Chen T-Y, Giovannucci E. Cigarette smoking and colorectal cancer incidence and mortality: Systematic review and meta-analysis. Int J Cancer. 2009; 124(10): 2406-2415.

29. Wu S, Feng B, LI K, Zhu X, Liang S, Liu X, et al. Fish consumption and colorectal cancer risk in humans: A systematic review and metaanalysis. Am J Med. 2012; 125(6): 551-559.e5.

30. Oddone E, Modonesi C, Gatta G. Occupational exposures and colorectal cancers: A quantitative overview of epidemiological evidence. World J Gastroenterol. 2014; 20(35): 12431-12444.

31. Alexander DD, Weed DL, Cushing CA, Lowe KA. Meta-analysis of prospective studies of red meat consumption and colorectal cancer. Eur J Cancer Prev. 2011; 20(4): 293-307.

32. Bardou M, Barkun AN, Martel M. Obesity and colorectal cancer. Gut. 2013; 62(6): 933-947. 